\title{
Synthesis of Cyclic Peroxides via Enyne-RCM/Diels-Alder Reaction Sequence
}

\author{
Young-Keun Yang, Susie Lee, and Jinsung Tae \\ Center for Bioactive Holectlar Hybrids (CBMH) and Department of Chemistry, Yonsei Lniversitw, Seoul 120-749, Korea \\ Recened JuIy 21, 2004
}

Key Words : Cyclic peroxides. Cyclic hỵdroxỵlamines. Diels-Alder reactions. Enỵne metathesis. Singlet oxygen

The sequence of an enyne ring-closing metathesis (eny'ne$\mathrm{RCM}^{1.2}$ followed by a Diels-Alder reaction has been applied widely in organic synthesis for the expeditious generation of molecular complexity. Although several dienophiles have been employed to date in Diels-Alder reactions of the cyclic conjugated dienes generated from enyne-RCM. singlet oxygen has not been one of them. The conjugated dienes 5 . which are readily obtained by enyne-RCM. could be reacted with singlet oxtgen ${ }^{3}$ to generate the corresponding cyclic peroxides 6 . as shown in Scheme 1. The cyclic peroxide unit is a component of many biologically important structures: furthermore. it can be transformed into several other valuable skeletons. For example, reductive cleavage of the $\mathrm{O}-\mathrm{O}$ bond could generate allylic diols. ${ }^{+}$Base- or transition metal-catalyzed $\mathrm{O}-\mathrm{O}$ bond cleavage followed by dehydration. is a well-known reaction strategy to synthesize furans. ${ }^{40.5}$ We have recently reported the synthesis of 1.2oxaza and 1.2-diaza heterocycles. having a diverse range of scaffolds. by ring-closing metathesis. ${ }^{67}$ Herein. we report our recent results on the synthesis of cyclic peroxides by Diels-Alder reactions between singlet oxygen and enyneRCM adducts.

The substituted enyne substrates 3 were prepared from the secondary alcohols 2 and $N$-Boc-protected alky'nyl hydroxylamines 1 under the Mitsunobu conditions (Scheme 1). The eny'nes 3 were treated with Grubbs' catalyst ta according to our previously reported procedure $e^{6 / 5}$ to give the enyne-RCM adducts 5 in moderate to good yields (Table 1). For substrates $3 \mathrm{e}$ and $3 \mathrm{~g}$. more reactive second generation Grubbs' catalyst $\mathbf{4 b}$ was used for the metathesis reactions (Table 1. entries 5 and 7 ).

The substituted conjugated dienes $\mathbf{5}$ and previously synthesized ones ${ }^{\text {b }}$ were utilized in the cycloaddition reaction with singlet oxygen. Acetonitrile solutions of the dienes and a catalytic amount of rose Bengal sensitizer were irradiated using a 400-W tungsten lamp while a steady flow of oxygen was passed though the solution. The reaction flask was cooled in an ice-bath during this procedure. Table 2 summarizes the results of these cycloaddition reactions. The formation of 6a from the corresponding enyne-RCM adduct was complete after $7 \mathrm{~h}$ : this product was isolated in $73 \%$ yield (Table 2, entry 1). The analogous peroxide $6 \mathrm{~b}$ was obtained in $82 \%$ yield (Table 2 , entry 2 ). The homologues with adjacent 7 - and 8-membered 1.2-oxaza rings were also

Table 1. Synthesis of Conjugated Dienes by Enyne-RCM

Entry

Reaction time and concentrations. "Isolated vields. "Used 10 mol'. of th, toluene. reflux.

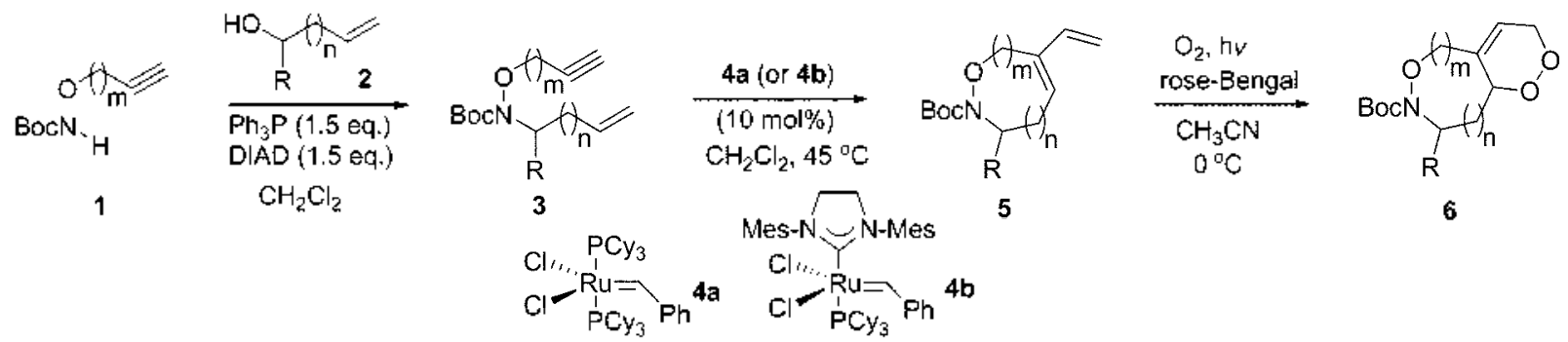

Scheme 1 
Table 2. Diels-Alder Reactions of Conjugated Dienes with Singlet Oxygen ${ }^{\prime}$

Entry

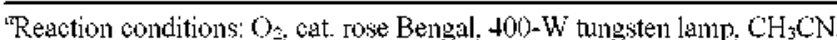
$0{ }^{\circ} \mathrm{C}$. "Reaction time. 'The yield in parenthesis is based on the recovered starting material. "The relative stereochemistries were determined by noe experiments.

prepared in good yields (Table 2 . entries 3 and 4 ).

Next. we examined dienes featuring greater degrees of substitution on either their 1,2-oxaza or 1,2-dioxine ring. Trisubstituted peroxide $6 \mathrm{e}$ was synthesized in $69 \%$ yield (Table 2. entry 5). Additional substituents on the 1.2-oxaza rings results in the generation of two diastereoisomeric products. In general. substituents on the carbon atom adjacent to the ring-forming sites produced the higher diastereoisomeric ratios. The peroxides $6 f$ and $6 \mathbf{j}$ were obtained as single diastereoisomers and $6 \mathrm{~g}$ was obtained as the major product in a $4: 1$ ratio (Table 2 . entries 6,10 . and 7. respectively). On the other hand. compounds having substituents positioned one extra carbon atom away from the ring-forming sites exhibited poor diastereoselectivity - they yielded nearly equal amounts of their two diastereoisomers but the yields of their products are comparable to those of the other reactions (Table 2, entries 8 and 9).

In conclusion, we have shown that the reaction sequence of an enyne-RCM followed by a [4+2] cycloaddition with singlet oxygen is synthetically valuable method for the synthesis of cyclic peroxides. By this reaction sequence, we have synthesized several cyclic peroxides fused with a cyclic hydroxylamine ring.

Acknowledgement. This work was supported by Center for Bioactive Molecular Hybrids (CBMH).

\section{References}

1. For selected recent reviews on olefin metathesis. see: (a) Grubbs. R. H.; Chang. S. Tetrahedron 1998, 5t, 4113 . (b) Fürstner. A. Angew: Chent. Int. Ed 2000. 39, 3012

2. For reviews on enye-metathesis. see: (a) Diver, S. T.: Giessert, A. J. Chem. Rev 2004. 104. 1317. (b) Poulsen. C. S.: Madsen. R. Synthesis 2003. I. (c) Mori. M. Top. Organomet. Chem. 1998. 1 . 133.

3. For recent examples of [4-2] yycloadditions of singlet oxygen. see: (a) Adam, W: Bosio. S. G.: Degen, H.-G.; Krebs. O.: Stalke. D.; Schumacher D. Eur J. Org. Chem 2002, 3944. (b) Griesbeck. A. G.: Bartoschek. A. Chem. Conmum. 20012. 1594. (c) Tung. M: Ham. J.: Song. T. Org. Lett 2002. 4.2763.

4. (a) Hioki. H:: Ooi. H.: Hamano. M.: Mimura. Y.: Yoshio. S.: Kodama, M: Ohta. S.: Yanai. M.: Ihegami, S. Tetrahedron 2001 57. 1235. (b) Suzuki, M: Oda, Y.; Hamanaka, N.: Noyori, R. Heterocycles $1990,30.517$. (c) Mueller. P.: Rodriguez, D. Heh Chin Acta 1985.68.975.

5. (a) Atasoy. B.: Ozen. R. Tetrahedron 1997. 53. 13867. (b) Suzuki. M.: Ohtake. H.: Kameya. Y: Hamanaka. N.: Noyori. R. J. Ong Chent 1989, 54, 5292. (c) Mahindroo, V. K. Singh, V: Dev, S. Ind J. Chem, Sect B 1988. 27B, 1080. (d) OShea, K. E.: Foote. C. S. J. Org Chem. 1989, 54. 3475 . (e) Kohmoto. S.: Kasai. S: Yamamoto. M: Yamada. K. Chem. Lett. 1988. 1477. (f) Harirchian. B.: Magnus. P. D. Synth. Commm. 1977. 7. 119.

6. (a) Yang. Y.-K.: Tae. J. Sylen 2003. 1043. (b) Yang. Y.-K.: Tae. T. Smlett 2003, 2017. (c) Tae, J; Hahn, D.W. Tetrahedron Lett. 2004. $+5,3757$.

7. (a) Koide, K.; Finkelstein. Z. B.: Verdine. G. L. J. Am. Chem. So. 2001. 123. 398. (b) Miyabe. H.: Yoshida. K.: Matsumura. A.: Yamauchi. M.: Takemoto. Y. Sylett 2003. 567.

8. Representative procedire for the singlet ongen Diels-Alder reaction: An acetonitrile solution ( $5 \mathrm{~mL}$ ) of the RCM adduct ( 100 $\mathrm{mg}, 0.4 .4 \mathrm{mmol}$ ) and a catalytic amount of rose Bengal bengal sensitizer $(2 \mathrm{mg}$ ) was irradiated using a $400 \mathrm{-W}$ tungsten lamp while a steady flow of oxygen was passed though the solution. The reaction flask was cooled in an ice-bath during this procedure. After 6 h. the solvent was removed under reduced pressure and the residue mixture was column chromatographed on silica gel (elution with $5^{\circ} \%$ ethyl acetate in hexanes) to give $86 \mathrm{mg}\left(75^{\circ} \%\right)$ of 6c. Spectral data for 6 c: colorless oil: $R_{\mathrm{f}}=0.2$ (silica gel, hexane: $\mathrm{EtOAc}=2: 1):{ }^{1} \mathrm{H}$ NMR $\left(500 \mathrm{MHz} . \mathrm{CDCl}_{3}\right) \delta=5.79$ (s. lH). $4.68-4.61$ (m. $3 \mathrm{H}) .4 .56-4.48(\mathrm{~m} .2 \mathrm{H}) .3 .99$ (d. $J=13.4 \mathrm{~Hz} . \mathrm{lH})$. $3.34-3.28(\mathrm{~m} .1 \mathrm{H}) .2 .26-2.24(\mathrm{~m} .1 \mathrm{H}) .2 .14-2.11(\mathrm{~m} . \mathrm{lH}) .1 .49(\mathrm{~s}$. $9 \mathrm{H}):{ }^{13} \mathrm{C} \mathrm{NMR}\left(62.9 \mathrm{MHz}, \mathrm{CDCl}_{3}\right) \delta=155.7 .137 .2,120.7 .81 .9$. $79.0,75.1 .69 .8,46.3,32.6 .28 .7$, IR (film. $\mathrm{cm}^{-1}$ ) 2976. 2930. 1706. 1404. 1368. $1251,1168,1117$; HRMS: $m z$ aled. for $\mathrm{C}_{12} \mathrm{H}_{1} \mathrm{NO}_{5}(\mathrm{M}+\mathrm{H})^{-}: 258.1341$ : found: 258.1343 